\title{
Fatigue crack growth analysis of pre-strained 7475-T7351 aluminum alloy
}

\author{
Kassim S. Al-Rubaie ${ }^{\text {a }}$, Emerson K.L. Barroso ${ }^{\text {a }}$, Leonardo B. Godefroid ${ }^{\text {b,* }}$ \\ ${ }^{a}$ EMBRAER (Empresa Brasileira de Aeronáutica), Av. Brigadeiro Faria Lima 2170, 12227-901 São José dos Campos, SP, Brazil \\ ${ }^{\mathrm{b}}$ Deptartamento de Engenharia Metalúrgica e de Materiais, Universidade Federal de Ouro Preto, \\ Escola de Minas, Praça Tiradentes 20, 35400-000 Ouro Preto, MG, Brazil
}

Received 6 December 2004; received in revised form 9 June 2005; accepted 10 September 2005 Available online 20 December 2005

\begin{abstract}
Aluminum alloys are widely used in aeronautical design due to their good mechanical properties and low densities. Among these alloys, 7475 (Al-Zn-Mg-Cu), modified from 7075, is successfully used due to strength similar to that of 7075 and superior fracture toughness. In this study, strips of 7475-T7351 were subjected to two tensile pre-strain levels of 3 and 5\%. Using compact tension C(T) specimens, fatigue crack growth (FCG) tests were conducted in air under constant amplitude loading at a stress ratio of 0.5 . Three FCG rate models, namely Collipriest, Priddle, and modified Forman were examined. The results showed that both fracture toughness and FCG resistance decreased with an increase in the prestrain level. Both Collipriest and Priddle models fit the FCG rate data in a similar fashion. However, the Priddle model provided a better fit than Collipriest. The modified Forman model provided the best fit to the FCG rate data as compared with the other two models. The modified Forman model used to fit other unpublished FCG data and its response was also superior to the others. Therefore, this model may be suggested for use in critical applications, such as aeronautical structural design.
\end{abstract}

(C) 2005 Elsevier Ltd. All rights reserved.

Keywords: 7475-T7351; Pre-strain; Fatigue crack growth rate; Statistical analysis; Modeling

\section{Introduction}

High strength age-hardenable aluminum alloys, such as $2 \mathrm{xxx}$ and $7 \mathrm{xxx}$, have been the most widely used structural materials in aeronautical industries due to their good mechanical properties and low densities [1-8].

The copper and magnesium bearing alloys $(2 \mathrm{xxx})$ are widely used for aircraft and space vehicles. The naturally aged and cold worked 2024-T3 is the most popular alloy of this group due to its good damage tolerance [2-5]. However, in the form of thick sheet, this alloy is susceptible to exfoliation corrosion $[2,9]$.

The zinc and magnesium bearing alloys (7xxx), of which 7075 is the most widely used, have the highest strengths by far. In the conventional peak-aged temper (T6), the thick plates, forgings, and extrusions of $7 \mathrm{xxx}$ series alloys are susceptible to stress corrosion cracking (SCC) [2,9-11]. The over-aged

\footnotetext{
* Corresponding author. Tel.: +55 313551 3012/1586; fax: +55 313551 3012.

E-mail address: leonardo@demet.em.ufop.br (L.B. Godefroid).
} doi:10.1016/j.ijfatigue.2005.09.008

temper (T7) has been developed to improve the SCC resistance; however, this results in loss of strength compared with the T6 temper $[12,13]$.

The need for high strength coupled with good fracture toughness and SCC resistance led to the development of 7475 alloy [14]. This progress resulted from a considerable reduction in the levels of iron, silicon, and manganese, but also from improvements in thermomechanical and heat treatment practices $[2,15]$.

In some cases, 7475-T7351 is being used after application of certain levels of pre-strain. Regarding the influence of prestraining on FCG behavior, few works [16-19] have been published. Hence, the objectives of this study are to: (a) show the effect of pre-strain on FCG rate in 7475-T7351, and (b) test different FCG models to determine which model provides the best-fit to the experimental data. To achieve these objectives, FCG data of 7475-T7351 subjected to two tensile pre-strain levels of 3 and $5 \%$ were collected. Due to the sigmoidal shape of the $\log (\mathrm{d} a / \mathrm{d} N)-\log (\Delta K)$ curve, three models, namely, Collipriest [20,21], Priddle [22], and modified Forman [23] were chosen. They model all three regions of the FCG rate curve. Nonlinear statistical analyses [24,25] were done to estimate the model parameters and to show which model best fits the FCG rate data. 
Table 1

Chemical composition of 7475 aluminum alloy (wt\%)

\begin{tabular}{llllllllll}
\hline Alloy & $\mathrm{Si}$ & $\mathrm{Fe}$ & $\mathrm{Cu}$ & $\mathrm{Mn}$ & $\mathrm{Mg}$ & $\mathrm{Zn}$ & $\mathrm{Cr}$ & $\mathrm{Ti}$ & $\mathrm{Al}$ \\
\hline 7475 & 0.029 & 0.085 & 1.661 & 0.01 & 2.376 & 5.722 & 0.21 & 0.0266 & Balance \\
\hline
\end{tabular}

\section{Material and experimental procedure}

\subsection{Material and specimens}

Aluminum alloy plate of 7475-T7351 with a thickness of $76.2 \mathrm{~mm}$ was used in this study. The chemical composition is shown in Table 1. Strips of $6 \mathrm{~mm}$ thickness, shown in Fig. 1, were machined from the original plate and then subjected to two tensile pre-strain levels of 3 and 5\%. From these strips, tensile test specimens, illustrated in Fig. 2, were machined in the longitudinal direction, according to ASTM E8 [26]. The $\mathrm{C}(\mathrm{T})$ specimens used for fracture toughness and FCG tests were machined in L-T direction, according to ASTM E647 [27]; the specimen dimensions are shown in Fig. 3.

\subsection{Fatigue crack growth testing}

FCG tests were conducted on pre-cracked $\mathrm{C}(\mathrm{T})$ specimens using the method described in ASTM E 647 [27]. FCG tests were done under a constant amplitude sinusoidal wave loading at a stress ratio $(R)$ of 0.5 . This stress ratio was suggested to reduce the crack closure effect [28]. FCG tests were conducted using a $100 \mathrm{kN}$ MTS servo-hydraulic testing machine interfaced to a computer for machine control and data acquisition. All tests were conducted at a frequency of $30 \mathrm{~Hz}$ under room temperature conditions that ranged from 20 to $25{ }^{\circ} \mathrm{C}$ with a relative humidity from 60 to $70 \%$ in air. The crack length was measured using a compliance method, in which a clip gauge is used to measure the elastic compliance of the specimen, which tends to increase with crack growth.

In addition, FCG threshold $\left(\Delta K_{\text {th }}\right)$ tests were done using a 'load shedding' method proposed in ASTM E647 [27]. Basically, these tests were conducted where the stress intensity factor range $\left(\Delta K=K_{\max }-K_{\min }\right)$ was decreased. Consequently, crack growth slowed down and the FCG threshold was reached as the crack stopped growing, or reached a sufficiently low

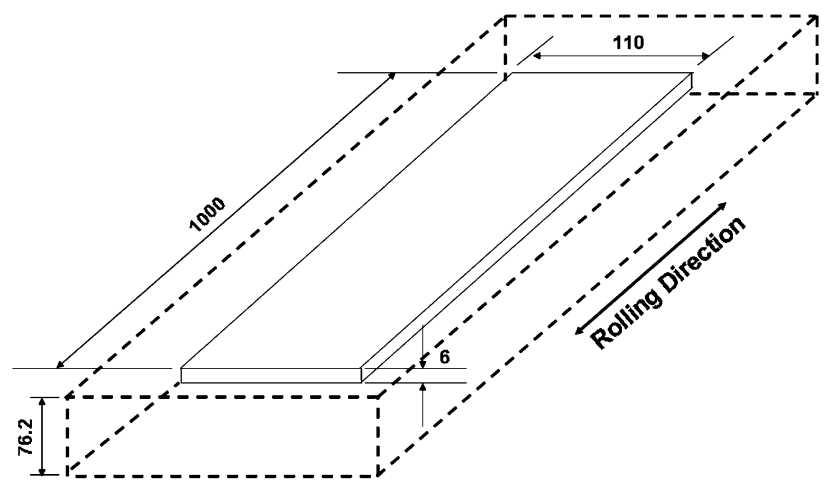

Fig. 1. Dimensional details of 7475-T7351 aluminum alloy plate and the strip (dimensions in millimeter).
FCG rate. According to ASTM E647, $\Delta K_{\text {th }}$ is about the $\Delta K$ corresponding to a FCG rate $(\mathrm{d} a / \mathrm{d} N)$ of $10^{-10} \mathrm{~m} /$ cycle.

\subsection{Fracture toughness testing}

Fracture toughness tests were conducted on the $\mathrm{C}(\mathrm{T})$ specimens, using an MTS servo-hydraulic testing machine, according to ASTM E561 [29]. Basically, cyclic loading was applied to introduce a fatigue crack. As the crack reached the desired length, the fatigue cycling was stopped, and the load was gradually increased until fracture occurred. The stress intensity at fracture was calculated as the fracture toughness. All tests were done at room temperature and in air environment.

\section{Results and discussions}

\subsection{Tensile test}

The results of tensile tests are presented in Table 2. Both $0.2 \%$ yield and ultimate tensile strength increase with an increase in the pre-strain level from 0 to $5 \%$. On the other hand, the total strain to fracture decreases. These results are expected due to the effect of strain-hardening [30,31].

\subsection{Fatigue threshold and fracture toughness}

Table 3 shows the results of the threshold stress intensity factor range $\left(\Delta K_{\mathrm{th}}\right)$ and fracture toughness $\left(K_{\mathrm{c}}\right)$ tests of $7475-$ T7351 for all cases of pre-strain studied. The fracture toughness decreases with an increase in the pre-strain level. This is expected and is attributed to the effect of strainhardening that leads to an increase in strength of the material. When the strength increases, the strain-hardening exponent decreases. This favors the formation and nucleation of microvoids with void sheet occurrence. This limits crack-tip opening displacement, thereby decreasing fracture toughness [32]. However, a general relation between the fatigue threshold and pre-strain was not found, since fatigue threshold is sensitive to many intrinsic and extrinsic features [33,34].

\subsection{Fatigue crack growth rate modeling}

\subsubsection{FCG rate models}

The reason for building models is to link theoretical ideas with the observed data. Modeling of FCG rate data has enhanced the ability to create damage tolerant design philosophies. Paris and Erdogan [35] proposed the most important and popular work. They were the first who correlated FCG rate with fracture mechanics parameters $\left(K_{\min }\right.$ and $\left.K_{\max }\right)$, describing the loading conditions in the region of the crack 


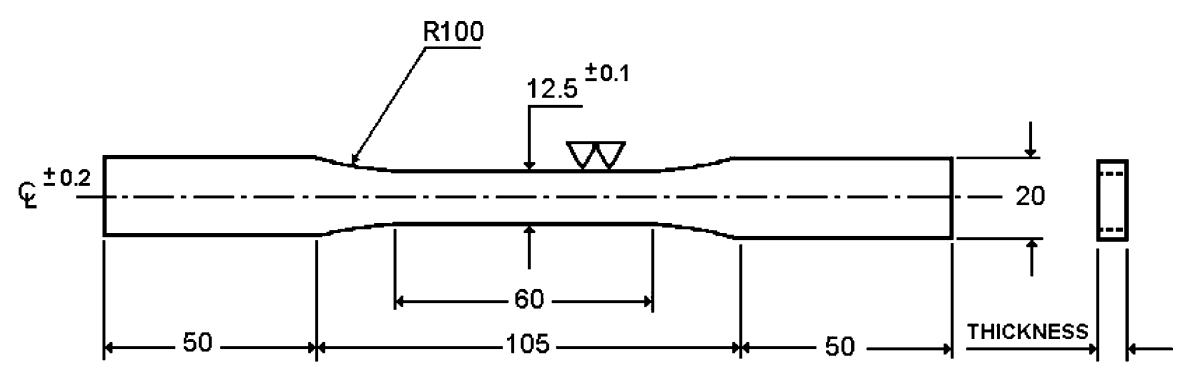

Fig. 2. Dimensional details of the tensile test specimen (dimensions in millimeter).

front. They observed a linear relationship between FCG rate $(\mathrm{d} a / \mathrm{d} N)$ and $\Delta K$ when plotted on a $\log -\log$ scale. Paris and Erdogan proposed the power law relationship:

$\frac{\mathrm{d} a}{\mathrm{~d} N}=C \Delta K^{n}$

where $C$ and $n$ are material parameters that are determined experimentally.

The Paris-Erdogan equation does not consider: (a) the effect of stress ratio, (b) the existence of fatigue threshold, and (c) the accelerated FCG rate when the maximum stress intensity factor $\left(K_{\max }\right)$ approaches material fracture toughness $\left(K_{\mathrm{c}}\right)$. It does not adequately describe region I or III FCG rates; it tends to overestimate region I and underestimate region III FCG rates. Although the Paris-Erdogan equation is a simplification of a very complex phenomenon, it is still very popular on account of significant engineering interest.

The typical curve of a $\log (\mathrm{d} a / \mathrm{d} N)-\log (\Delta K)$, at a prescribed condition (environment and stress ratio), is sigmoidal in shape. It comprises three regions and is bounded at its extremes by the threshold stress intensity factor range and the critical stress intensity factor range. In the intermediate region of the curve,

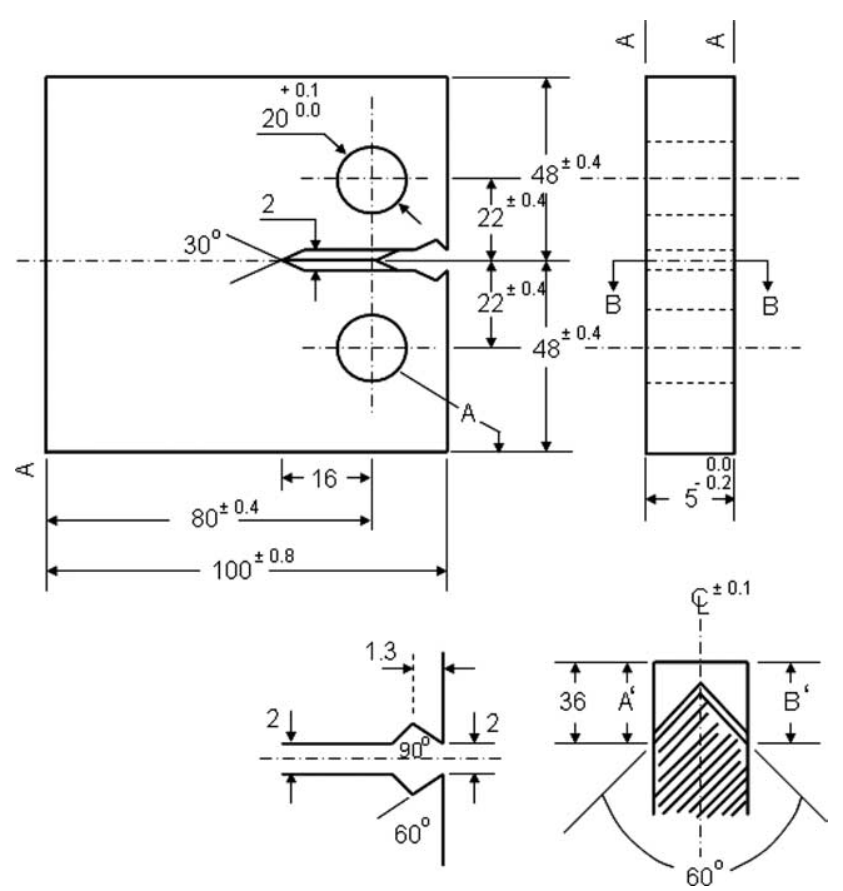

Fig. 3. Dimensional details of the $\mathrm{C}(\mathrm{T})$ specimen (dimensions in millimeter). there is a linear relation between $\log (\mathrm{d} a / \mathrm{d} N)$ and $\log (\Delta K)$, as proposed by Paris and Erdogan.

Based on Eq. (1), different FCG rate models have been proposed to fit all or part of the sigmoidal curve. In this study, three models that fit all parts of FCG curve are adopted. These models are:

\section{Collipriest model}

Collipriest proposed the following model [20,21]:

$\log \frac{\mathrm{d} a}{\mathrm{~d} N}=C_{1}+C_{2} \tanh ^{-1}\left[\frac{\log \left(\frac{\Delta K^{2}}{\Delta K_{\mathrm{th}} K_{\mathrm{c}}(1-R)}\right)}{\log \left(\frac{K_{\mathrm{c}}(1-R)}{\Delta K_{\mathrm{th}}}\right)}\right]$

where

$C_{1}=\log \left(C\left(K_{\mathrm{c}} \Delta K_{\mathrm{th}}\right)^{n / 2}\right) \quad$ and $\quad C_{2}=\log \left(\frac{K_{\mathrm{c}}}{\Delta K_{\mathrm{th}}}\right)^{n / 2}$

\section{Priddle model}

Priddle proposed the following model [22]:

$\frac{\mathrm{d} a}{\mathrm{~d} N}=C\left(\frac{\left(\Delta K-\Delta K_{\mathrm{th}}\right)(1-R)}{\left((1-R) K_{\mathrm{c}}-\Delta K\right)}\right)^{n}$

Table 2

Average room temperature tensile test properties of 7475-T7351 for all prestrain cases

\begin{tabular}{llllr}
\hline $\begin{array}{l}\text { Pre-strain } \\
\text { level }\end{array}$ & Orient. & $\sigma_{\mathrm{YS}}(\mathrm{MPa})$ & $\sigma_{\mathrm{TS}}(\mathrm{MPa})$ & $\varepsilon(\%)$ \\
\hline $0 \%$ & $\mathrm{~L}$ & 405.76 & 482.60 & 12.11 \\
$3 \%$ & $\mathrm{~L}$ & 412.17 & 496.38 & 9.82 \\
$5 \%$ & $\mathrm{~L}$ & 416 & 497.67 & 8.82 \\
\hline
\end{tabular}

$\sigma_{\mathrm{YS}}, 0.2 \%$ yield tensile strength; $\sigma_{\mathrm{TS}}$, ultimate tensile strength; $\varepsilon$, total strain.

Table 3

Fatigue threshold and fracture toughness values of 7475-T7351 for all prestrain cases

\begin{tabular}{lll}
\hline Pre-strain level $(\%)$ & $\Delta K_{\mathrm{th}}\left(\mathrm{MPa} \mathrm{m}^{0.5}\right)$ & $K_{\mathrm{c}}\left(\mathrm{MPa} \mathrm{m}^{0.5}\right)$ \\
\hline 0 & 1.31 & 95.5 \\
3 & 1.45 & 92.8 \\
5 & 1.37 & 79.3 \\
\hline
\end{tabular}


Table 4

Statistical analysis results of 7474-T7351 FCG rate data for $0 \%$ pre-strain, $R=0.5$, comparison among Collipriest, Priddle, and modified Forman models

\begin{tabular}{|c|c|c|c|c|c|c|c|}
\hline Model & Parameter & Estimate & Standard error & $t$-value & $p$-value & $95 \%$ LCI & $95 \%$ UCI \\
\hline \multirow[t]{4}{*}{ Collipriest } & $C$ & $2.364 \mathrm{E}-09$ & $5.091 \mathrm{E}-10$ & 4.6428 & $<0.001$ & $1.355 \mathrm{E}-09$ & 3.372E-09 \\
\hline & $n$ & 1.407 & 0.05145 & 13.3837 & $<0.0001$ & 1.199 & 1.615 \\
\hline & $\mathrm{Se}$ & 0.3279 & $R^{2}$ & 0.8895 & $F$-value & 934 & \\
\hline & SSF & 12.4697 & $R_{\text {adj }}^{2}$ & 0.8886 & $p$-value & $<0.0001$ & \\
\hline \multirow[t]{4}{*}{ Priddle } & $C$ & $3.587 \mathrm{E}-06$ & $6.41 \mathrm{E}-07$ & 5.9377 & $<0.0001$ & $2.390 \mathrm{E}-06$ & 4.783E-06 \\
\hline & $n$ & 1.558 & 0.044507 & 34.9991 & $<0.0001$ & 1.470 & 1.646 \\
\hline & $\mathrm{Se}$ & 0.2900 & $R^{2}$ & 0.9135 & $F$-value & 1224.9 & \\
\hline & SSE & 9.7551 & $R_{\text {adj }}^{2}$ & 0.9127 & $p$-value & $<0.0001$ & \\
\hline \multirow{4}{*}{$\begin{array}{l}\text { Modified For- } \\
\text { man }\end{array}$} & $C$ & 4.003E-09 & $2.628 \mathrm{E}-10$ & 15.2308 & $<0.0001$ & $3.482 \mathrm{E}-09$ & 4.52E-09 \\
\hline & $n$ & 2.582 & 0.039212 & 65.8420 & $<0.0001$ & 2.504 & 2.659 \\
\hline & $\mathrm{Se}$ & 0.1323 & $R^{2}$ & 0.9819 & $F$-value & 6301.4 & \\
\hline & SSE & 2.0342 & $R_{\text {adj }}^{2}$ & 0.9817 & $p$-value & $<0.0001$ & \\
\hline
\end{tabular}

SSE, sum of squares of error; Se, standard error of the residual; $R^{2}$, coefficient of determination; $R_{\text {adj }}^{2}$, adjusted coefficient of determination; LCI, lower confidence interval; UCI, upper confidence interval.

Table 5

Statistical analysis results of 7474-T7351 FCG rate data for 3\% pre-strain, $R=0.5$, comparison among Collipriest, Priddle, and modified Forman models

\begin{tabular}{|c|c|c|c|c|c|c|c|}
\hline Model & Parameter & Estimate & Standard error & $t$-value & $p$-value & $95 \%$ LCI & $95 \% \mathrm{UCI}$ \\
\hline \multirow[t]{4}{*}{ Collipriest } & $C$ & $1.178 \mathrm{E}-09$ & $1.466 \mathrm{E}-10$ & 7.9958 & $<0.0001$ & $8.31 \mathrm{E}-10$ & $1.461 \mathrm{E}-09$ \\
\hline & $n$ & 1.910 & 0.052626 & 36.2871 & $<0.0001$ & 1.806 & 2.013 \\
\hline & $\mathrm{Se}$ & 0.2394 & $R^{2}$ & 0.9462 & $F$-value & 4223.2 & \\
\hline & SSE & 137571 & $R_{\text {adj }}^{2}$ & 0.9460 & $p$-value & $<0.0001$ & \\
\hline \multirow[t]{4}{*}{ Priddle } & $C$ & $8.754 \mathrm{E}-06$ & $6.278 \mathrm{E}-07$ & 13.9433 & $<0.0001$ & 7.517E-06 & $9.991 \mathrm{E}-06$ \\
\hline & $n$ & 1.750 & 0.023382 & 75.8493 & $<0.0001$ & 1.704 & 1.796 \\
\hline & $\mathrm{Se}$ & 0.2068 & $R^{2}$ & 09589 & $F$-value & 5602.5 & \\
\hline & SSE & 102672 & $R_{\text {adj }}^{2}$ & 0.9587 & $p$-value & $<0.0001$ & \\
\hline \multirow{4}{*}{$\begin{array}{l}\text { Modified For- } \\
\text { man }\end{array}$} & $C$ & $3.560 \mathrm{E}-09$ & $1953 \mathrm{E}-10$ & 18.2214 & $<0.0001$ & 3.17E-09 & 3.94E-09 \\
\hline & $n$ & 2.720 & 0.026429 & 102.9073 & $<0.0001$ & 2.668 & 2.772 \\
\hline & $\mathrm{Se}$ & 0.1265 & $R^{2}$ & 0.9846 & $F$-value & 15339.7 & \\
\hline & SSE & 3.8460 & $R_{\mathrm{adj}}^{2}$ & 0.9845 & $p$-value & $<0.0001$ & \\
\hline
\end{tabular}

SSE, sum of squares of error; Se, standard error of the residual; $R^{2}$, coefficient of determination; $R_{\mathrm{adj}}^{2}$, adjusted coefficient of determination; LCI, lower confidence interval; UCI, upper confidence interval.

Table 6

Statistical analysis results of 7474-T7351 FCG rate data for 5\% pre-strain, $R=0.5$, comparison among Collipriest, Priddle, and modified Forman models

\begin{tabular}{|c|c|c|c|c|c|c|c|}
\hline Model & Parameter & Estimate & Standard error & $t$-value & $p$-value & $95 \% \mathrm{LCI}$ & $95 \% \mathrm{UCI}$ \\
\hline \multirow[t]{3}{*}{ Collipriest } & C & $1.726 \mathrm{E}-09$ & $3.944 \mathrm{E}-10$ & 1.3770 & $<0.001$ & $9.427 \mathrm{E}-10$ & $2.510 \mathrm{E}-09$ \\
\hline & $n$ & 1.772 & 0.097834 & 18.1142 & $<0.0001$ & 1.578 & 1.967 \\
\hline & $\mathrm{Se}$ & 0.2655 & $R^{2}$ & 0.9367 & $F$-value & 1317.5 & \\
\hline \multirow[t]{3}{*}{ Priddle } & $C$ & $5647 \mathrm{E}-06$ & $6.664 \mathrm{E}-07$ & 8.4730 & $<0.0001$ & 4.332E-06 & $6.971 \mathrm{E}-06$ \\
\hline & $n$ & 1.665 & 0.039927 & 41.6928 & $<0.0001$ & 1.585 & 1.744 \\
\hline & $\mathrm{Se}$ & 0.2313 & $R^{2}$ & 0.9513 & $F$-value & 1738.3 & \\
\hline \multirow{4}{*}{$\begin{array}{l}\text { Modified For- } \\
\text { man }\end{array}$} & C & 3.946E-09 & $3.588 \mathrm{E}-10$ & 10.9993 & $<0.0001$ & 3.23E-09 & 4.66E-09 \\
\hline & $n$ & 2.667 & 0.044118 & 60.4521 & $<0.0001$ & 2.579 & 2.755 \\
\hline & $\mathrm{Se}$ & 0.1329 & $R^{2}$ & 0.9838 & $F$-value & 5412.5 & \\
\hline & SSE & 1.5711 & $R_{\text {adj }}^{2}$ & 0.9836 & $p$-value & $<0.0001$ & \\
\hline
\end{tabular}

SSE, sum of squares of error; Se, standard error of the residual; $R^{2}$, coefficient of determination; $R_{\mathrm{adj}}^{2}$, adjusted coefficient of determination; LCI, lower confidence interval; UCI, upper confidence interval. 


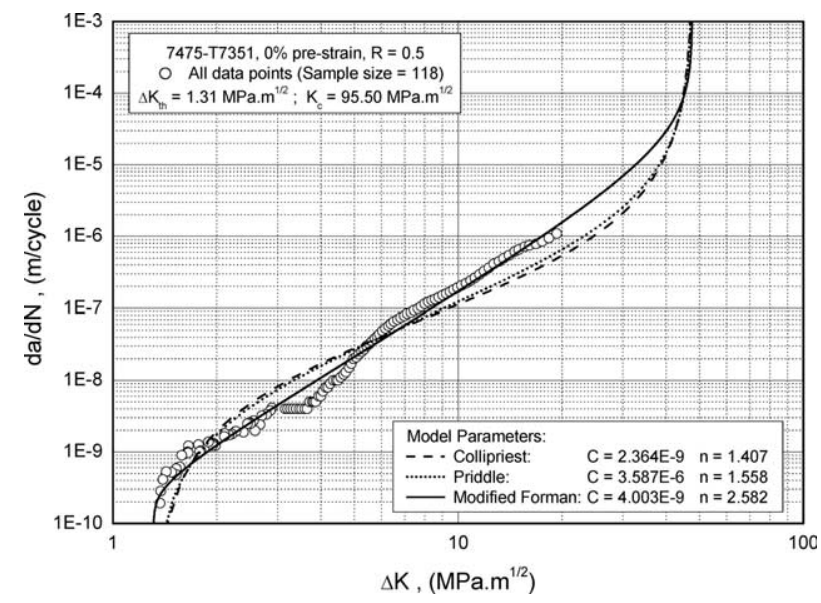

Fig. 4. FCG rate curves of 7475-T7351, $0 \%$ pre-strain, $R=0.5$, comparison among Collipriest, Priddle, and modified Forman models.

\section{Modified Forman model}

Forman proposed its modified model [23] as:

$$
\frac{\mathrm{d} a}{\mathrm{~d} N}=\frac{C(1-R)^{m} \Delta K^{n}\left(\Delta K-\Delta K_{\mathrm{th}}\right)^{p}}{\left((1-R) K_{\mathrm{c}}-\Delta K\right)^{q}}
$$

Certain values of the exponents $m, p$, and $q$ of Eq. (4) give other forms of the crack growth equation as indicated below:

\begin{tabular}{ll} 
Exponent value & Equation form \\
\hline$m=p=q=0$ & Paris \\
$m=p=0$ and $q=1$ & Forman \\
$p=q=0$ and $m=\left(m_{\mathrm{w}}-1\right)^{\mathrm{n}}$ & Walker
\end{tabular}

Collipriest, Priddle, and modified Forman models are nonlinear regression models. A nonlinear model has at least one parameter (quantity to be estimated) that appears nonlinearly [24,25]. Nonlinear regression is an iterative procedure, and the basis used for estimating the unknown parameters is the criterion of least squares. The fitting procedure provides (i) parameters, (ii) error estimate on the parameter, and (iii) a statistical measure of goodness of fit.

The least squares criterion quantifies goodness of fit as the sum of squares of the vertical distances of the data points from the assumed model. That is, the best model for a particular data set is that with the smallest sum of squares. In fact, it is not simple to compare models with different parameters. The problem is that a more complicated model (more parameters) gives more flexibility (more inflection points) for the curve being generated than the curve being defined by a simpler model (fewer parameters). Thereby, the sum of squares of a more complicated model tends to be lower.

Both Collipriest and Priddle models use two parameters $(C$ and $n$ ), while the modified Forman contains five parameters $(C$, $n, m, p$, and $q$ ). The objective of the exponent $m$ is to control the spread of the FCG rate curve for different values of $R$. For the case of constant $R$, the exponent can be taken as zero, reducing the model parameters to four. In addition, $p$ and $q$ may be used as constants, reducing the model parameters to two. For metallic materials, since the values of $p$ and $q$ are between 0 and 1 , they were chosen by trial end error to be 0.25 and 0.75 , respectively. Finally, both $C$ and $n$ of the selected models may be estimated using nonlinear regression analysis.

\subsubsection{Parameter estimation}

The estimated parameters $(C$ and $n)$ and the statistical properties obtained for all pre-strain cases studied and models selected are presented in Tables 4-6. The estimated curves are presented in Figs. 4-6.

For the $0 \%$ pre-strain case, Fig. 4 shows that the modified Forman model provides a better fit to the FCG rate data as compared to the other two models. The Collipriest and Priddle models fit the data in a similar fashion; however, the latter fits relatively better than the former.

The estimated parameters $(C$ and $n$ ) of the modified Forman model are the most significant parameters. This may be confirmed by examination of $t$-value and related $p$-value of

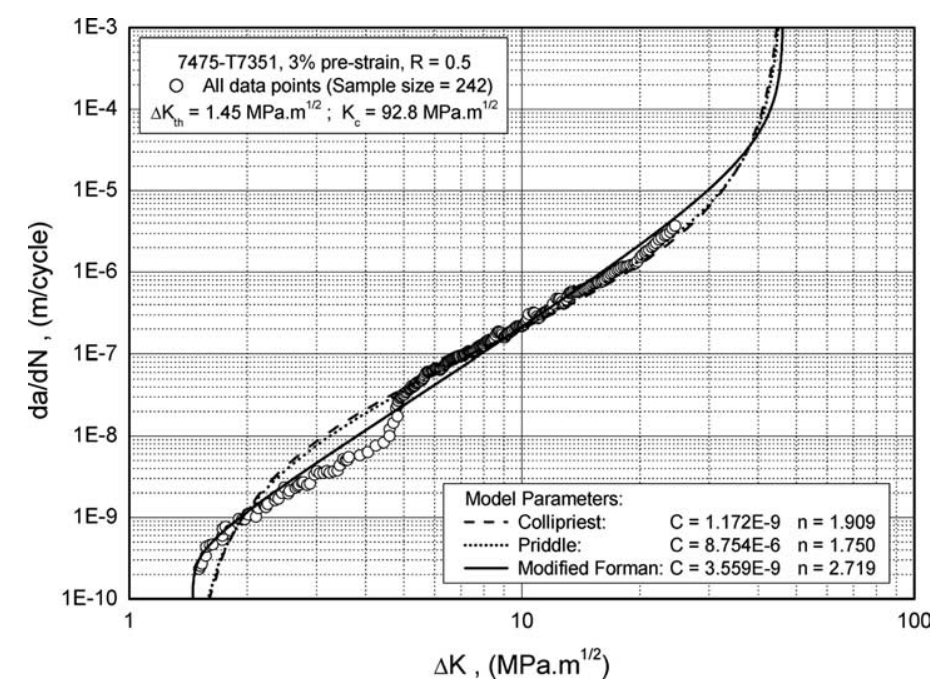

Fig. 5. FCG rate curves of 7475-T7351, 3\% pre-strain, $R=0.5$, comparison among Collipriest, Priddle, and modified Forman models. 


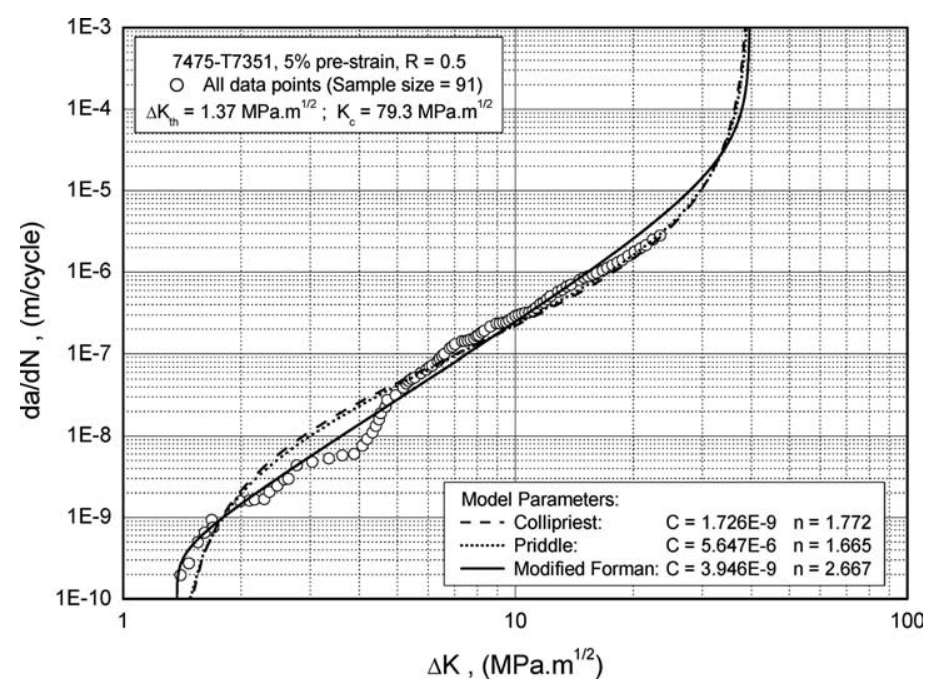

Fig. 6. FCG rate curves of 7475-T7351, $5 \%$ pre-strain, $R=0.5$, comparison among Collipriest, Priddle, and modified Forman models.

the estimates for each model (Table 4). The $t$-value is the ratio of the parameter estimate to its standard error, the latter being used to compute confidence intervals of the estimate. Generally, a high $t$-value associated with a parameter estimate indicates that the estimate is well determined in the model and the confidence band will be narrow. Conversely, a low $t$-value indicates that the estimate is poorly determined and the confidence band will be wide. An indication of high or low $t$-value of an estimate depends on the related $p$-value (probability) and significance level used. For a 0.05 significance level, an estimate is statistically significant when its $t$-value is high enough to provide a $p$-value less than the significance level chosen.

From Table 4 , at the 0.05 and 0.01 levels of significance, it is concluded that the parameters $(C$ and $n)$ estimated from the three models are statistically significant, since their $p$-values are smaller than both levels of significance. The modified
Forman parameters are more significant due to their larger $t$-values.

\subsubsection{Goodness of fit}

There are several statistical measures that may be used to assist the goodness of fit of a model used with the experimental data. These are: $R^{2}, R_{\text {adj }}^{2}, F$-value, standard error of the residual (Se), Schwarz's Bayesian Information Criterion (BIC), and Akaike's Information Criterion (AIC) [36]. The $R^{2}$ statistic may be used for comparing models having the same number of parameters. Other statistical methods may be used for comparing models that have an equal or different numbers of parameters. Selection of the best model should be based on other considerations than just the value of one model selection statistic.

In this study, a comparison among the FCG rate models chosen was based on $R^{2}, R_{\text {adj }}^{2}, F$-value, and standard error of the residual (Se). Large values of $R^{2}, R_{\mathrm{adj}}^{2}$, and $F$ statistics coupled

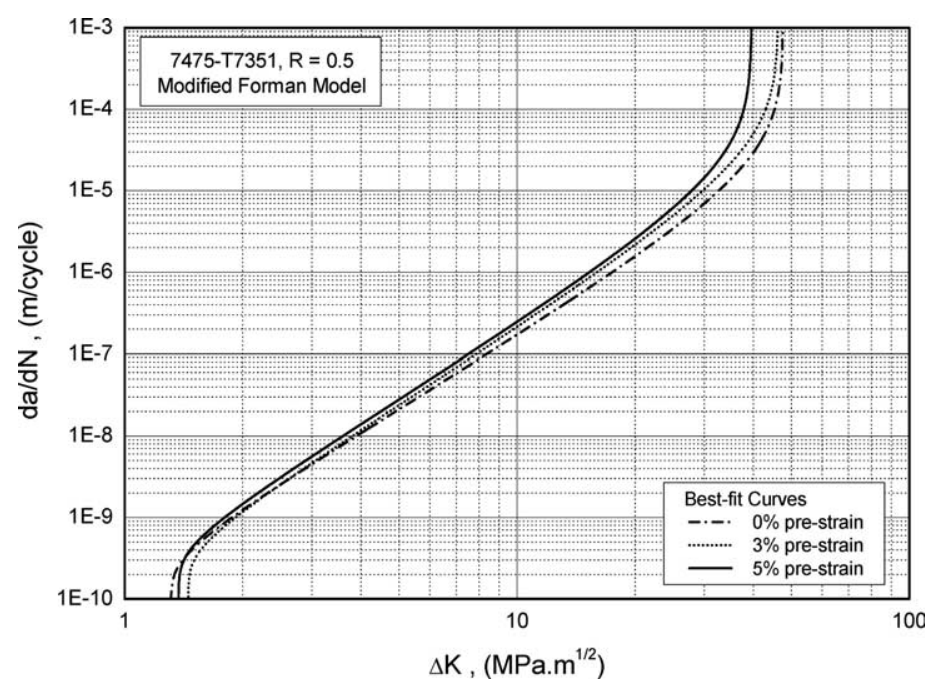

Fig. 7. Effect of pre-strain on the FCG rate of 7475-T7351, $R=0.5$, modified Forman model. 
with a small value of Se indicate that the model explains the data well. From Table 4, all statistical measures determined from the modified Forman model indicate that this provides the best fit as compared with the other two models. Also, the Priddle model fits the data better than the Collipriest one.

A visual examination of the curves presented in Fig. 4 reveals that the modified Forman curve comes close to the data points in both the threshold and Paris regions as compared to the curves generated by Collipriest and Priddle models.

For the case of 3\% pre-strain (Table 5 and Fig. 5) and 5\% pre-strain (Table 6 and Fig. 6), the same results outlined for the case of $0 \%$ pre-strain were found. This implies that the modified Forman model fits the FCG rate data better than the Priddle model, which fits relatively better than the Collipriest model.

\subsection{Effect of pre-strain on the FCG rate}

The modified Forman model provides a better fit to the FCG rate data when compared with the other two models. Hence, it is used to show the effect of pre-strain on FCG rate. Fig. 7 shows that an increase in pre-strain level has no appreciable influence in the near-threshold region (region I) and in the Paris region (region II). However, in the unstable region (region III), a considerable effect can be seen, where an increase in pre-strain from 0 to $5 \%$ leads to a decrease in material fracture toughness and consequently alters the FCG behavior.

The Paris region is less sensitive to microstructural alterations as a result of the pre-strain applied. On the other hand, if pre-strain can change the microstructure, the threshold value will be affected. There are several factors that influence the near-threshold FCG rate, like grain size [37,38], dispersoids [39], precipitates [40,41], texture [42]. However, in Ref. [43] no appreciable effect of the pre-straining on the microstructure of 7475-T7351 was found. Therefore, it may be expected that the micromechanisms of fatigue crack growth are similar for all cases of pre-strain.

The SEM examination of the fracture surfaces in the nearthreshold region reveals that crack growth progressed by cyclic-cleavage with ductile striations (Fig. 8). Since there are no considerable differences in the severity of fatigue crack growth micromechanisms for the different pre-strain levels, it may be expected that the true mean threshold values are similar. This is shown in Table 3 , where the differences in the threshold value for the three conditions did not exceed $10 \%$.

The SEM examination of the fracture surfaces in the transition between threshold and Paris regions (Fig. 9) shows that the ductile striations are the dominant features. In this region, since there are no considerable differences in the severity of fatigue crack growth micromechanisms for the prestrain cases, it may be concluded, therefore, that the FCG rates are nearly the same.
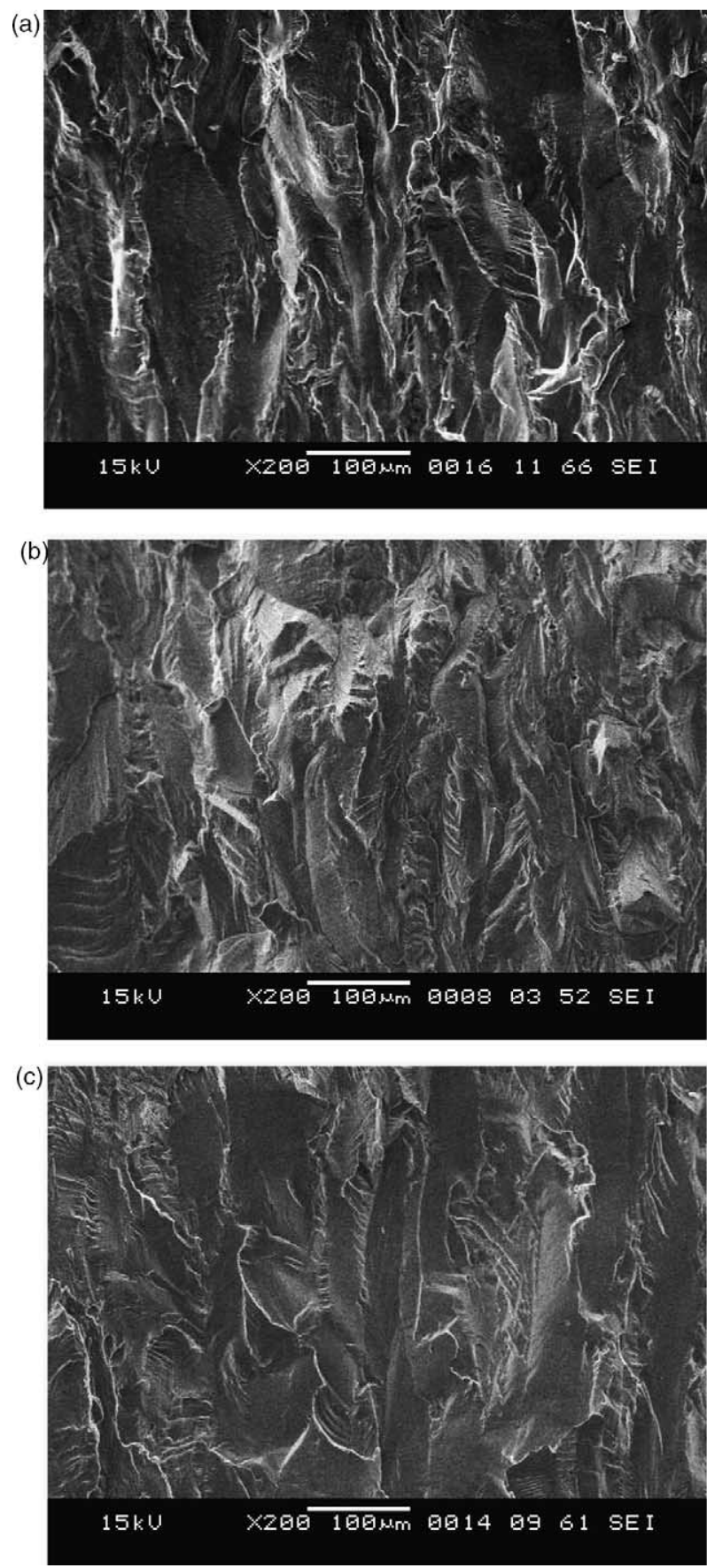

Fig. 8. SEM micrographs of the fracture surfaces in the near-threshold region, 7475-T7351. (a) $0 \%$ pre-strain, (b) $3 \%$ pre-strain, and (c) $5 \%$ pre-strain.

\section{Conclusions}

The FCG behavior of pre-strained 7475-T7351 aluminum alloy plate was studied. Two tensile pre-strain levels of 3 and $5 \%$ were applied. FCG tests were carried out at $R=0.5$ and the data collected were modeled using Collipriest, Priddle, and modified Forman models. From the results obtained, the following conclusions can be drawn:

1. The effect of pre-strain may be clearly seen in the unstable region, region III, where the increase of pre-strain leads to 

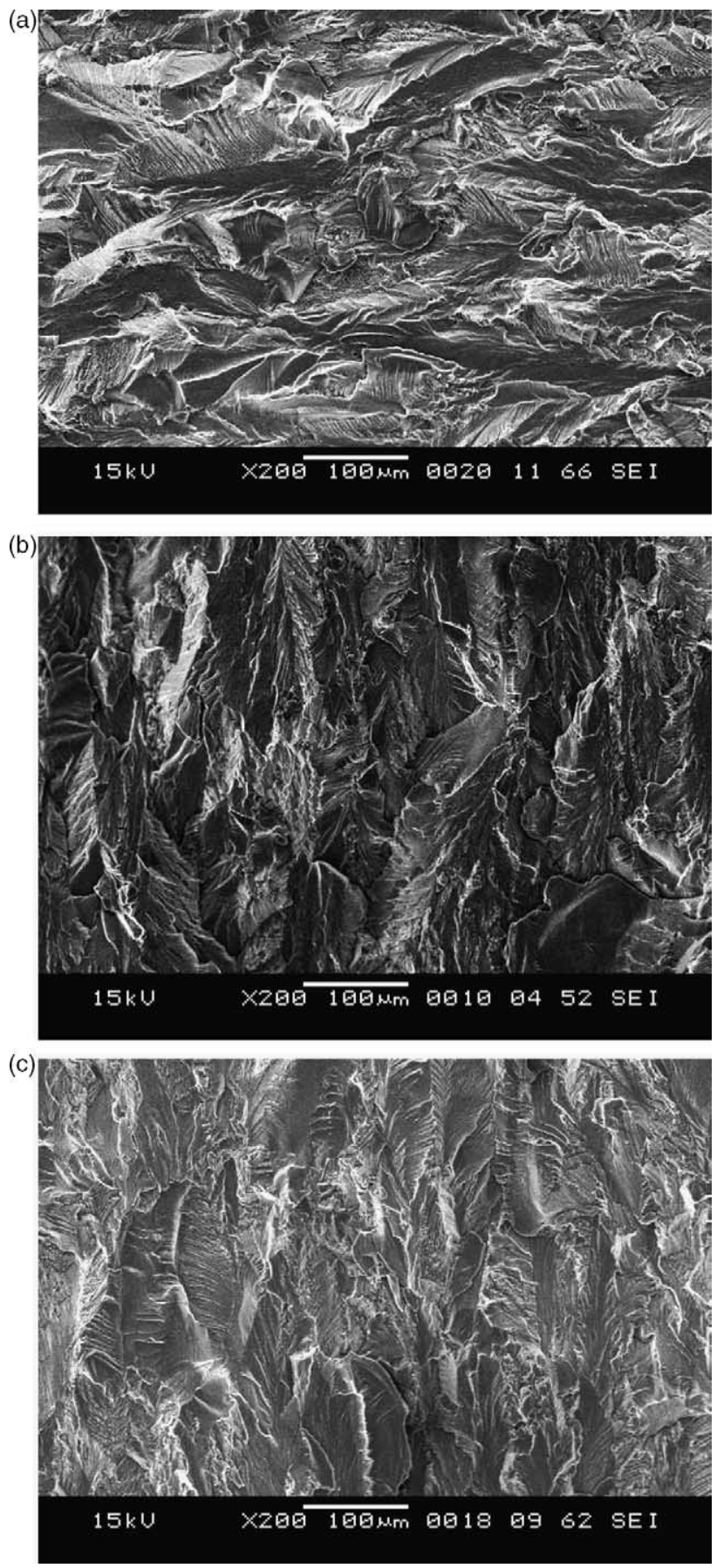

Fig. 9. SEM micrographs of the fracture surfaces in the transition between threshold and Paris regions, 7475-T7351. (a) 0\% pre-strain, (b) 3\% pre-strain, and (c) $5 \%$ pre-strain.

decrease material fracture toughness, thereby, increasing the FCG rates. The pre-strain has no considerable influence in the near-threshold region and in the Paris region.

2. Both Collipriest and Priddle models fit the FCG rate data sets in a similar fashion. However, the latter provides a better fit than the former one.

3. The modified Forman model provides the best fit to the FCG rate data sets as compared with the Collipriest and Priddle models. Therefore, this model may be suggested for use in critical applications, such as aeronautical structural design.

\section{References}

[1] Dorward RC, Pritchett TR. Advanced aluminium alloys for aircraft and aerospace applications. Mater Des 1988;9(2):63-9.

[2] Polmear IJ. Light alloys: metallurgy of the light metals. 2nd ed. London: Edward Arnold; 1989.

[3] Buhl H, editor. Advanced aerospace materials. Berlin: Springer; 1992.

[4] Imarigeon J-P, Holt RT, Koul AK, Zhao L, Wallace W, Beddoes JC. Lightweight materials for aircraft applications. Mater Charact 1994;35: 41-67.

[5] Starke Jr EA, Staley JT. Application of modern aluminum alloys to aircraft. Prog Aerosp Sci 1996;32:131-72.

[6] Rendigs K-H. Aluminium structures used in aerospace: status and prospects. Mater Sci Forum 1997;242:11-24.

[7] Heinz A, Haszler A, Keidel C, Moldenhauer S, Benedictus R, Miller WS. Recent development in aluminium alloys for aerospace applications. Mater Sci Eng A 2000;280(1):102-7.

[8] Williams JC, Starke Jr EA. Progress in structural materials for aerospace systems. Acta Mater 2003;51(19):5775-99.

[9] Wallace W, Hoeppner DW, Kandachar PV. Aircraft corrosion: causes and case histories. AGARD AG 278, vol. 1, 1985.

[10] Koch GH. Stress-corrosion cracking and hydrogen embrittlement. In: Fatigue and fracture, ASM handbook, vol. 19. ASM; 1996. p. 483-506.

[11] Vogt H, Speidel MO. Stress corrosion cracking of two aluminium alloys: a comparison between experimental observations and data based on modeling. Corros Sci 1998;40(2/3):251-70.

[12] Lifka BW. SCC resistant aluminum alloy 7075-T73 performance in various environments. Aluminum 1977;53(12):750-2.

[13] Sprowls DO, Spuhler EH. Avoiding stress-corrosion cracking in high strength aluminum alloy structures. Alcoa green letter, Alcoa, January 1982.

[14] Cieslak SJ, Mehr PL. Alcoa 7475 sheet and plate. Alcoa green letter. 4th revised ed, 1985.

[15] Smolej A, Gnamus M, Slacek E. The influence of the thermomechanical processing and forming parameters on superplastic behaviour of the 7475 aluminium alloy. J Mater Process Technol 2001;118(1-3):397-402.

[16] Radhakrishnan VM, Baburamani PS. An investigation of the effect of prestraining on fatigue crack growth. Mater Sci Eng 1975;17(2):283-8.

[17] Schijve J. The effect of pre-strain on fatigue crack growth and crack closure. Eng Fract Mech 1976;8(4):575-81.

[18] Wasén J, Karlsson B. Influence of prestrain and ageing on near-threshold fatigue crack growth in fine-grained dual-phase steels. Int J Fatigue 1989; 11(6):395-405.

[19] Nian L, Bai-Ping D. Effect of monotonic and cyclic prestrain on the fatigue threshold in medium-carbon steels. Int J Fatigue 1992;14(1):41-4.

[20] Collipriest JE. In: An experimentalist's view of the surface flaw problem. New York: ASME; 1972. p. 43-61.

[21] Collipriest JE, Ehret RM, Thatcher C. Fracture mechanics equations for cyclic growth. NASA technology utilization report, MFS-24447, 1973.

[22] Anderson TL. Fracture mechanics: fundamentals and applications. 2nd ed. West Palm Beach, FL: CRC Press; 1995.

[23] Carlson RL, Kardomateas GA. An introduction to fatigue in metals and composites. 1st ed. London: Chapman \& Hall; 1996.

[24] Ratkowsky DA. Nonlinear regression modeling: a unified practical approach. New York, NY: Marcel Dekker, Inc.; 1983.

[25] Bates DM, Watts DG. Nonlinear regression analysis and its applications. New York: Wiley; 1988.

[26] ASTM E8. Standard test methods for tension testing of metallic materials. Annual book of ASTM standards. ASTM; 2001.

[27] ASTM E647. Standard test method for measurement of fatigue crack growth rates. Annual book of ASTM standards. ASTM; 2001.

[28] Iacoviello F. Statistical behaviour of $\Delta K$ threshold values and life prediction analysis in $2091 \mathrm{Al}-\mathrm{Li}$ alloy. Int J Fatigue 2000;22:657-63. 
[29] ASTM E561. Standard practice for $R$-curve determination. Annual book of ASTM satandards. ASTM; 2001.

[30] Liaw PK, Landes JD. Effects of monotonic and cyclic prestrain on fracture toughness: a summary. In: Fracture mechanics: eighteenth symposium, ASTM STP 945. ASTM, 1988. p. 622-46.

[31] Bar-On I, Tuler FR, Howerton WM. Effect of prestrain on the J-resistance curve of HY-100 steel. In: Nonfracture mechanics, vol. II-elastic-plastic fracture, ASTM STP 995. ASTM, 1989. p. 244-58.

[32] Antolovich SD. Alloy design for fatigue and fracture. In: Fatigue and fracture, ASM handbook, vol. 19. ASM; 1996. p. 27-41.

[33] McEvily AJ. Fatigue crack thresholds. In: Fatigue and fracture, ASM handbook, vol. 19. ASM; 1996. p. 134-52.

[34] Vasudévan AK, Bretz PE. Near-threshold fatigue crack growth behavior of 7XXX and 2XXX alloys: a brief review. In: Fatigue crack growth threshold concepts. The Metallurgical Society/AIME; 1984. p. 25-42.

[35] Paris PC, Erdogan F. A critical analysis of crack propagation laws. J Basic Eng 1963;December:528-34.

[36] Burnham KP, Anderson DR. Model selection and multimodel inference: a practical information-theoretic approach. 2nd ed. Berlin: Springer; 2002.
[37] Bretz PE, Petit JI, Vasudevan AK. The effects of grain size and stress ratio on fatigue crack growth in 7091 aluminum alloy. In: Fatigue crack growth threshold concepts. The Metallurgical Society/AIME; 1984. p. 163-83.

[38] Minakawa K, Levan G, McEvily AJ. The influence of load ratio on fatigue crack growth in 7090-T6 and IN9021-T4 P/M aluminium alloys. Metall Trans 1986;17A(10):1787-95.

[39] Harrison M, Martin JW. The effect of dispersoids on fatigue crack propagation in $\mathrm{Al}-\mathrm{Zn}-\mathrm{Mg}$ alloy. In: ECF6-fracture control of engineering structures, vol. 3. Engineering Materials Advisory Services Ltd; 1986. p. 1503-10.

[40] Rao KTV, Ritchie RO. Effect of prolonged high-temperature exposure on the fatigue and fracture behaviour of aluminium-lithium alloy 2090. Mater Sci Eng 1988;100(1/2):23-30.

[41] Rao KTV, Ritchie RO. Mechanical properties of aluminium-lithium alloys. Part II. Fatigue crack propagation. Mater Sci Technol 1989;5(9): 896-907.

[42] Yoder GR, Pao PS, Imam MA, Cooley LA. Unusual fracture mode in the fatigue of an Al-Li alloy. ICF7: Adv Fract Res 1989;2:919-27.

[43] Barros EKL. Effects of pre-straining and shot peening on the fracture toughness and fatigue crack growth rate in 7475-T7351 aluminium alloy. MSc thesis, Ouro Preto, MG, Brazil; 2004 [in Portuguese]. 